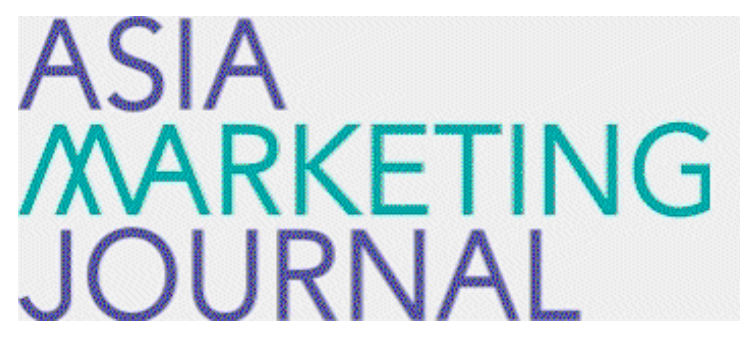

ASIA MARKETING JOURNAL

Volume 16 | Issue 3

Article 6

$10-31-2014$

\title{
Cultural Tunneling Effect
}

Seungkook Roh

Follow this and additional works at: https://amj.kma.re.kr/journal

Part of the Marketing Commons

\section{Recommended Citation}

Roh, Seungkook (2014) "Cultural Tunneling Effect," Asia Marketing Journal: Vol. 16 : Iss. 3 , Article 6. Available at: https://doi.org/10.15830/amj.2014.16.3.77

This Article is brought to you for free and open access by Asia Marketing Journal. It has been accepted for inclusion in Asia Marketing Journal by an authorized editor of Asia Marketing Journal. 


\title{
Cultural Tunneling Effect: Conceptual adoption \& Application in movie industry
}

\author{
Seungkook Roh*
}

Many researchers have analyzed the relationship between the financial success patterns of a motion picture and many other factors, such as the production cost, marketing, stars, awards, reviews, genre, and rating. Through these studies, many researchers and investors concluded that big budgets to make a blockbuster movie can serve as an insurance policy to meet their ROI; thus the box office is dominated by blockbuster movies. High-budget blockbuster movies are more likely to receive attention because these movies are more recognizable given their high expenses for production and casting. Therefore, audiences choose blockbusters in an effort to reduce the searching cost and to mitigate the possibility of a regrettable choice. This behavior of consumers, in turn, causes distributors to allocate screens for blockbusters, resulting in "concentration of blockbuster consumption." As such, low-budget films cannot easily become popular due to the lack of distribution. Indeed, low-budget films released on a small number of screens often end up becoming dismal failures. However, there are exceptional examples which are contrary to the general idea in the movie industry that a big budget and showings on a large number of screens can guarantee the success of a movie.

Although researchers have attempted to analyze the performances of movies with small budgets, such movies are likely to be regarded as outliers and then be entirely discarded, as they are far from the 'three-sigma' range, especially given that previous research methodologies could not explain the financial success of such unique examples. This study attempts to explain the financial success at the box office of low-budget movies by applying the concept of the tunnel effect in quantum mechanics, as the phenomenon found in the movie industry is similar to a particle's movement in quantum physics. The tunneling effect is a phenomenon by which a particle without enough energy to pass over a potential barrier tunnels through it. Adopting the analogy, this study draws a tunneling probability function and cultural constant to forecast other outliers using the Schrödinger equation. Moreover, the study finds that word-of-mouth creates in the movie industry this phenomenon of finding outliers.

Key words: movie industry, low-budget movie, tunneling effect, outlier

\footnotetext{
*Ph.D., KAIST(skroh@kaist.edu)
} 


\section{Introduction}

Movies are experience goods, as consumers cannot fully determine the quality prior to $\mathrm{ac}^{-}$ tually watching them. Also, the quality of movies cannot easily be standardized, as every film is a unique product and consumers' preferences are diverse. Such characteristics of movies pose difficulties in forecasting the performance of movies, making their production very risky from the viewpoint of investors and filmmakers.

In an effort to reduce such risks and improve profitability, investors and producers have attempted to find the key success factors of movies. Numerous researchers have also analyzed the relationship between the financial success of a motion picture and many factors, such as the production cost, marketing expenditures, the presence of major stars, whether it wins academy awards, how much critical acclaim is garnered, the genre, the rating and other factors.
According to prior studies, many researchers agree that the volume of box-office revenue in the movie industry is dominated by a few "blockbuster" movies (De Vany \& Walls, 1999) and that big budgets can serve as an insurance policy (S. Basuroy, S. Chatterjee, \& S.A. Ravid, 2003). High-budget blockbuster movies are more likely to receive attention because these movies are more recognizable due to their outlays of high expenses for marketing, big-name actors and special effects. Therefore, audiences choose blockbusters in order to reduce their search costs and to allay the possibility of an incorrect choice. This behavior of consumers, in turn, makes distributors allocate screens for blockbusters, resulting in a "concentration of blockbuster consumption." As such, low-budget films cannot easily become popular due to the lack of distribution. Indeed, low-budget films released on a small number of screens often fail. However, there exist exceptional examples which are contrary to the general idea that a

〈Figure 1〉 The relationship between the Concentration of Movie Consumption and Financial Success

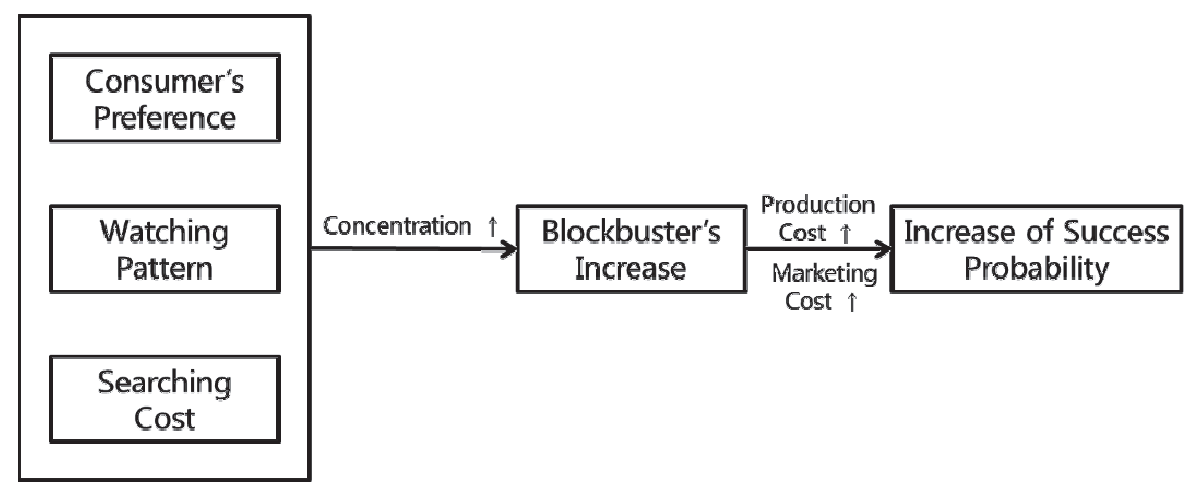


big budget and occupancy on a large number of screens can guarantee the success of a movie. Although there are few such movies, several low-budget films succeeded and became popular, recording high box-office numbers. For example, Rocky, Jaws, and Driving Miss Daisy all showed unexpected results. In particular, 'Paranormal Activity'1) (2009), which was produced for 15 thousand dollars, earned 193 million dollars internationally and was ranked first at the box office for a week (Oct 23-29, 2009). It is the most profitable film based on return on investment, showing an ROI of 433,900\%, which is regarded as a miracle in the movie industry. Likewise, the Korean movie "A Farm Partner" (2009) cost only one hundred thousand dollars to produce, but it earned more than ten million dollars.

However, when researchers study and analyze the performance of movies, such movies as these are likely to be regarded as outliers and then entirely discarded, as they are far from the three-sigma range. Outliers consist of observations that are numerically distant from the rest of the data. That is, an outlier is one that appears to deviate markedly from other members of the sample in which it occurs (Grubbs, 1969). "According to the three-sigma rule (or the 68-95-99.7 rule) in statistics, nearly all values empirically lie within three standard deviations of the mean in a normal distribution"

\section{(Wikipedia.org).}

This leads to the question of how we can explain the success of such exceptional cases. Is it appropriate to ignore such cases as outliers in studies? Previous research methodologies could not explain the financial success of such unique examples. Several studies attempted to explain the factors of success qualitatively using the Delphi method, questionnaire surveys, and market surveys, but there has thus far been no quantitative approach to account for success factors and to predict the possibility given the very small sample size of such cases.

This study attempts to explain the financial success at the box office of low-budget movies by applying the concept of the "tunneling effect" in quantum mechanics of natural science. Until now in social science fields, they have adopted a lot of theories from natural science when they cannot solve the problems or explain experience with existing social science methods. For examples, the gravity equation of Newton in international trade is widely used and there are many research findings (Bergstrand, 1985; Fratianni \& Kang, 2006; Piperakis, Milner, \& Wright, 2003) and Bernoulli equation is used to calculate traffic on the road (Chowdhury, Santen, \& Schadschneider, 2000; De Palma, Ben-Akiva, Lefevre, \& Litinas, 1983). The tunneling effect is the perception of a particle moving beyond an occluding object and then reappearing after

1) This movie was originally developed as an independent feature and given film festival screenings in 2007. 
a suitable amount of time on the other side of it. Classically, the particle cannot tunnel through the barrier. However, in the quantum world, mechanically the particle can penetrate the barrier and appear on the other side despite the fact that there is little possibility for it to tunnel through the barrier. Likewise, movies with low budgets rarely tunnel through the barrier posed by a big budget in the movie industry, but a few movies with low budgets become popular and successful at the box office. There are considerable analogies between these concepts in many ways. Thus, this study compares the attributes of the movie industry with those of physics and explains those outliers by adopting the concept of the tunneling effect in quantum mechanics.

\section{Literature review}

\subsection{Movie Industry}

Many researchers have tried to find the key success factors in order to forecast the performances of movies (Bagella \& Becchetti, 1999; Chakravarty, Liu, \& Mazumdar, 2010; De Vany \& Walls, 2004; De Vany \& Walls, 2002; Gazley, Clark, \& Sinha, 2011). Many variables, such as the marketing cost, word-of-mouth, the number of screens, the series and genre, the presence or absence of superstars, the product cost, movie awards, critics' reviews, MPAA ratings, the release date, and even the pattern of the release have been used in previous studies. Figure 2 shows the value chain of the movie industry, i.e., a series of activities from production to consumption along with the major variables as-

〈Figure 2〉 Value Chain of the Movie Industry and Key Success Variables

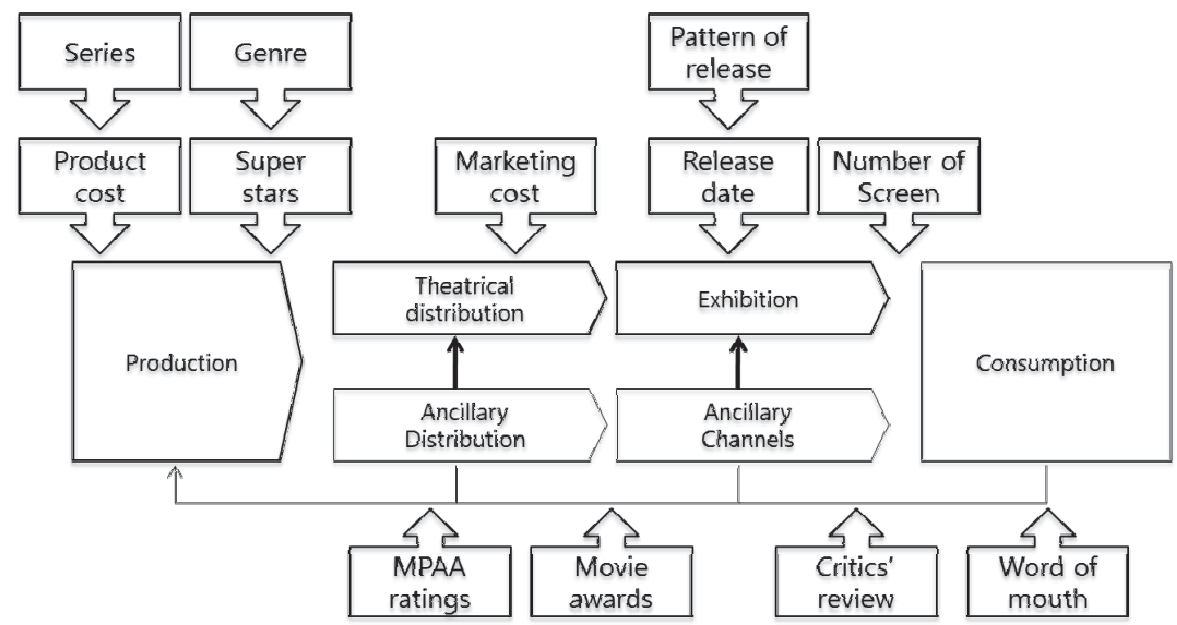

80 ASIA MARKETING JOURNAL Vol. 16 No. 03 October 2014 
sociated with box-office success.

\subsection{Success Factors Related to the Product Cost}

\subsubsection{Production cost}

All costs pertaining to the film's production are included, such as actors' salaries, editing, and scenery. Negative costs have received significant attention in the literature on motion picture economics (Litman, 1983; Prag \& Casavant, 1994; Ravid, 1999, 2004). Big budgets translate into lavish sets and costumes, expensive digital manipulations, and special effects such as those seen in the film Transformers: Age of extinction (budget, \$210million, released in 2014) and X-man: Days of future past (budget, \$200 million, released in 2014). Ravid (1999) and John, Ravid, and Sunder (2002) suggest that big budgets are correlated with higher revenue. Litman (1983) argues that big budgets reflect higher quality and greater box office popularity (Suman Basuroy, Subimal Chatterjee, \& S Abraham Ravid, 2003). The production cost is an indicator of a movie's quality (Prag \& Casavant, 1994). In general, however, big budgets are expected to show a noisy but positive correla- tion with film success. The same logic suggests that expenditures on advertising will be positively related to revenues (Prag \& Casavant, 1994). Sharda (2006) classifies a movie based on its box-office receipts in one of nine categories, ranging from 'flop' to 'blockbuster'.

\subsubsection{Star power}

Star power has received considerable attention in the literature (De Vany \& Walls, 1999; Holbrook, 1999; Neelamegham \& Chintagunta, 1999; Smith \& Smith, 1986; Sochay, 1994). Hollywood seems to favor films with stars, and it is almost axiomatic that a star's presence is a key to a film's success (Suman Basuroy et al., 2003). In contrast, Litman (1983) finds no significant relationship between a star's presence in a film and box-office revenues.

\subsubsection{Genre}

Genres include comedy, action, thriller, drama, horror, musical, science fiction, and others and occasionally combinations of these. The production cost varies depending on the genre. Musicals are by far the most expensive movies to produce on average. Action films are the

〈Table 1〉 Classification of Movie by Product Cost Range (Sharda, 2006)

\begin{tabular}{cccccccccc}
\hline Class No. & 1 & 2 & 3 & 4 & 5 & 6 & 7 & 8 & 9 \\
\hline Range & $\langle 1$ & $>1$ & $>10$ & $>20$ & $>40$ & $>65$ & $>100$ & $>150$ & $>200$ \\
(in Millions) & (Flop) & $\langle 10$ & $\langle 20$ & $\langle 40$ & $\langle 65$ & $\langle 100$ & $<150$ & $<200$ & (Blockbuster) \\
\hline
\end{tabular}


second most expensive to make but the second lowest in terms of quality. Assuming studios are rational about how they spend money to produce films, this suggests that 'action' is a dimension along which movie fans and movie critics have a different notion of quality. Comedies have the lowest cost and the lowest quality, but aside from that, the genres do not display a predictable pattern of cost-quality tradeoffs. The genres of blockbuster films are generally science fiction, action, musical, and such movies are mainly produced by major studios.

\subsubsection{Number of screen}

The number of manufactured movies is endless, but the number of screens is limited. If a distributor confirms most screens, consumers are limited in terms of their choice of a movie at the cinema. Thus, the importance of confirming screen increases. The number of screens is positively correlated with the production cost.

Genre and casting stars are related to production cost as shown in Figure 3.

\subsection{Success Factors Related to Word-of-Mouth}

\subsubsection{Review}

Realizing the importance of reviews to the box-office success of films, studios often strategically manage the review process by excerpting positive reviews in their advertising and delaying or forgoing advance screenings if they anticipate bad reviews (Suman Basuroy et al., 2003). Both positive and negative reviews are correlated with weekly box-office revenue over an eight-week period (Suman Basuroy et al., 2003)

\subsubsection{MPAA ratings}

Motion picture rating systems vary widely from one country to another. In the United States, MPAA ratings include the following five ratings: G (General audiences. All ages admitted), PG (Parental guidance suggested. Some material may not be suitable for children), PG-13 (Parents strongly cautioned. Some

〈Figure 3〉 The Elements of Production Cost

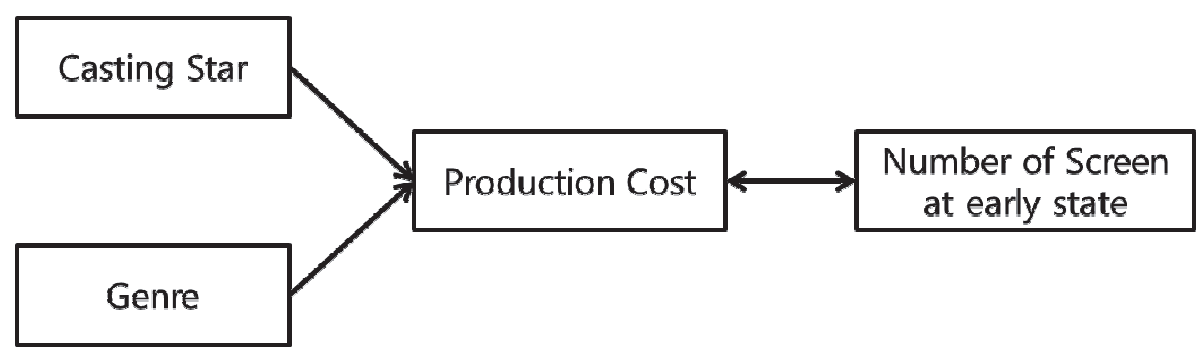


material may be inappropriate for children under 13), R (Restricted. Children under 17 require accompanying parent or adult guardian), and NC-17 (No one 17 and under admitted). Similarly, in Korea, the ratings are classified as G, 12, 15 and 18. According to previous research, movies rated $\mathrm{PG}-13$ attract the most people to movie theatres. Thus, blockbuster films are generally rated $\mathrm{PG}-13$.

\subsubsection{Word-of-mouth:}

Movie awards and critics' reviews along with MPAA ratings are conceptually and strongly related to word-of-mouth. When people receive information regarding an award given to a movie, they want to see the movie, according to the experience of the movie industry. Thus, producers and distributors hope to win an award such as an Academy Award or an award from the Berlin movie festival. After winning an award, the movie's box-office take dramatically increases in general. Concerning critics' reviews, their importance increases day by day due to the increased power of the internet. The internet environment has changed our way of communicating. Large portal service companies such as Yahoo and Google have movie review pages which deliver movie information. Almost every movie is updated on the web at these portal service sites.

Movie awards, reviews and MPAA ratings are related to word-of-mouth (WOM), as shown in Figure 4. Among many variables, the key variables for financial success number only two: the production cost and WOM. When calculating the tunneling probability, the movement of these two variables is used.

\subsection{Tunneling Effect}

The tunneling effect is a phenomenon by which a particle without enough energy to pass over a potential barrier tunnels through it. When particles without sufficient energy to penetrate a wall (E(particle Energy) < V(Potential Energy)) reach a potential barrier, they bounce back in classical mechanics. However, in quantum me-

〈Figure 4〉 The Construction of Word of Mouth

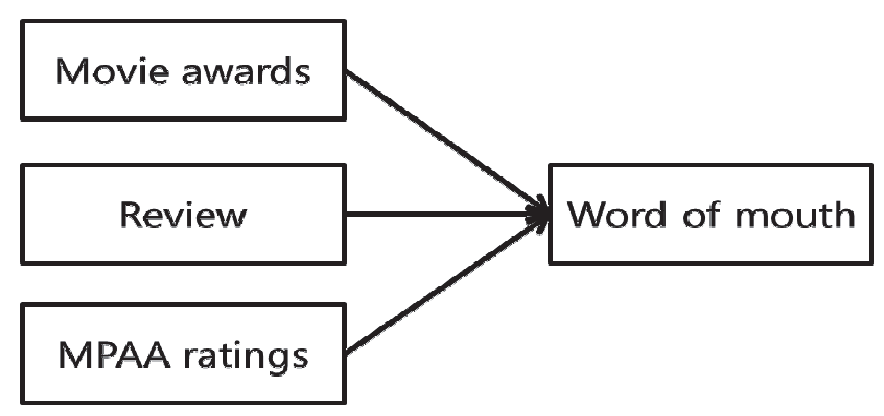

Cultural Tunneling Effect: Conceptual adoption \& Application in movie industry 83 


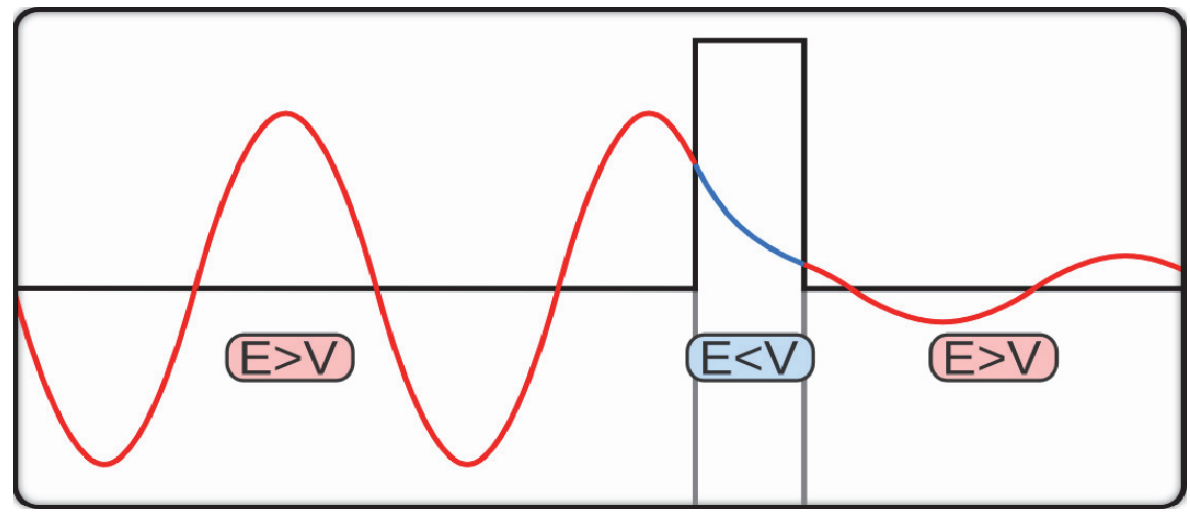

chanics, these particles can, with a very small possibility, tunnel to the other side, thus crossing the barrier.

The reason for this phenomenon stems from the treatment in quantum mechanics as having the properties of waves and particles. The wave function can be solved using the Schrödinger equation because the Schrödinger equation is mathematically a type of wave equation. A wave function describes the quantum state of a particle and how it behaves.

Existing research methodology could not explain the financial success of such unique $\mathrm{ex}^{-}$ amples contrary to the conventional success. Some previous studies tried to explain the successful factors qualitatively, but there was no quantitative approach to account for the success factors and predict the possibility with very small sample size of such cases. In this study, this explores the use of a tunnel effect concept of quantum mechanics in explaining the financial performance of movies consuming low-budget at the box-office. That is, previous studies regarding a financial success of movies have accounted for the lack of low-budget movies because of limited samples. This study tries to develop an Econophysics methodology to explain those exceptional successful cases of low budget movies by applying the concept of "tunnel effect" in quantum mechanics. Tunnel effect is known as physically inspired analytical techniques, capable of modeling quantum world as well as tunnel effect means that a very small particle was little possibility to go through the face barrier.

In this research, there are three fundamental theories that are outliers, tunneling effect and wave so as to develop a new theory. First, movie has an attribute of wave. To have a nature of wave, movie should get an attribute like interference and diffraction defined by natural science. 


\subsection{Physical Attribution of a Movie}

According to previous studies, movie may have an attribute of diffraction and interference. When two movies released together, we can find the effect of constructive diffraction and destructive diffraction. Thus, In order to reduce destructive interference among movies, distributors control their release date. One-sourcemulti-use is probable concept to give an explanation to this suggestion. So far, in field of culture study, many researches shows that cultural contents diffract to several areas like DVD, OST, Character, play, novel, sports, game etc. therefore, one-source-multi-use called snowball effect or window effect(Ainslie, Drèze, \& Zufryden, 2005; Baggett, 1979; Dalton et al., 2003; Sargent et al., 2004). Snowball effect means that revenue or sales is going bigger and bigger like snowball from acme of mountain covered with snow. This status seems that wave diffracted by prism has similar to status in Figure 6.

Besides, there is other practical evidence in movie industry that movie has an attribute of wave's interference according to relevant research concerning movies. Similar genre' released movies at the same time they could hardly be successful as moviegoers' selection are divided into each movie. On the other hands, when analogous genre' two or more movies released, they could take moviegoer's attention. That is, it has an effect to raise an expectation and interest in the movies. Thus, distributors should consider deciding their movie's released day after confirming competitors' movies release day and then setting their marketing strategies. For instance, when a war picture released, generally moviegoers could hardly watch another war picture. Totally, we mix the overall concepts of culture and physics to explain highly unique point called as outlier in movie industry. Tunneling effect could explain well the outlier than other

〈Figure 6〉 One-source-multi-use Concept in Contrast to Wave Diffraction in Physics
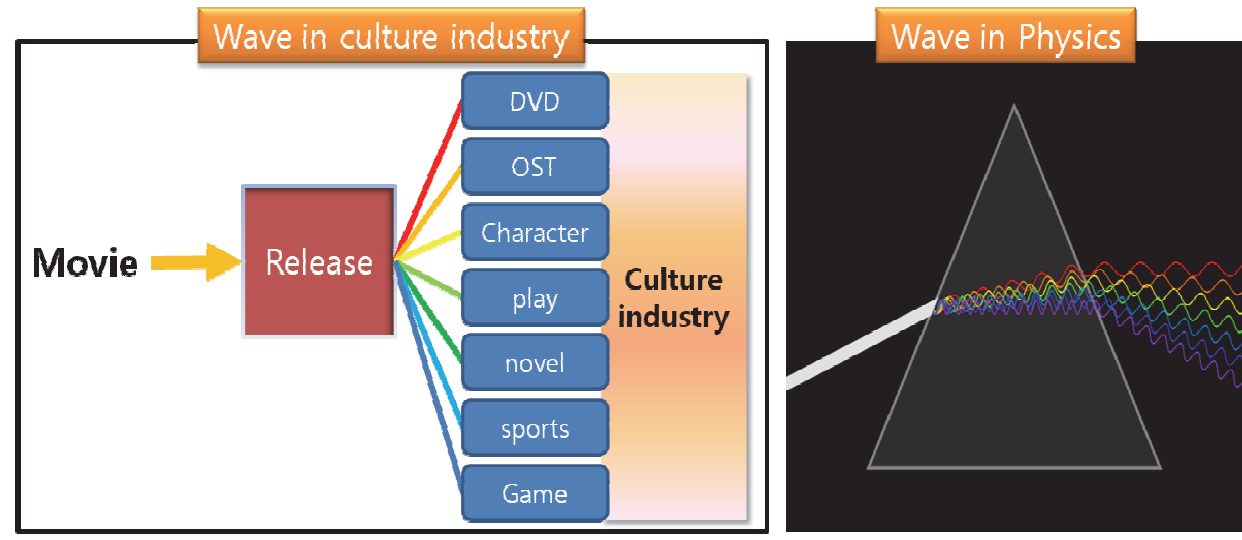
〈Figure 7〉 Wave interference in Physics

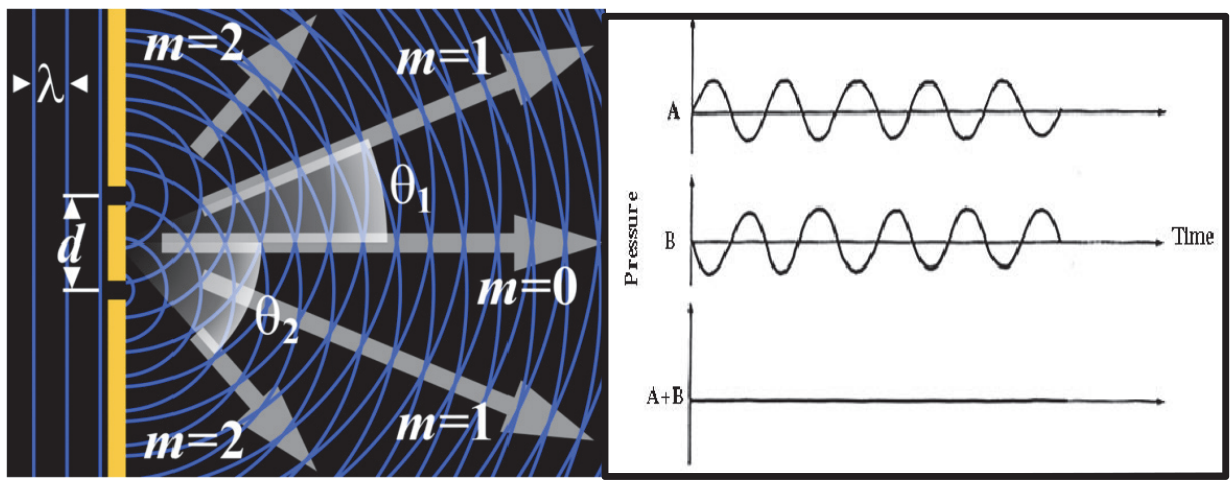

〈Figure 8〉 Movement of movie

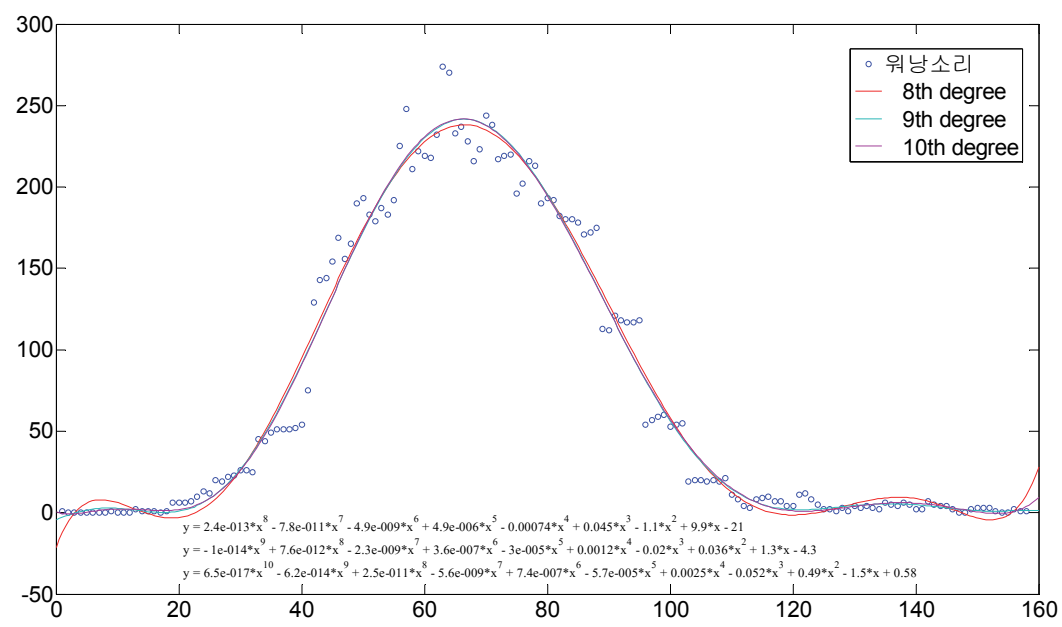

research methodologies which have limitation.

Figure 8 shows that there is an equation of III. Data and Variables movement of a movie. Using this equation we can get wave function of the movie like Figure 9. Thus, following this way and attribute of movie having a wave, we are able to adopt tunneling effect theory this paper.

In this study, data was collected from the Korean Film Council (KOFIC) and NAVER Movie, a popular Korean search portal. According to a market survey company in Korea, NAVER has $77 \%$ of the market share in Korea, surpassing other portal sites such as Google and 
〈Figure 9〉 Wave function of a movie's movement

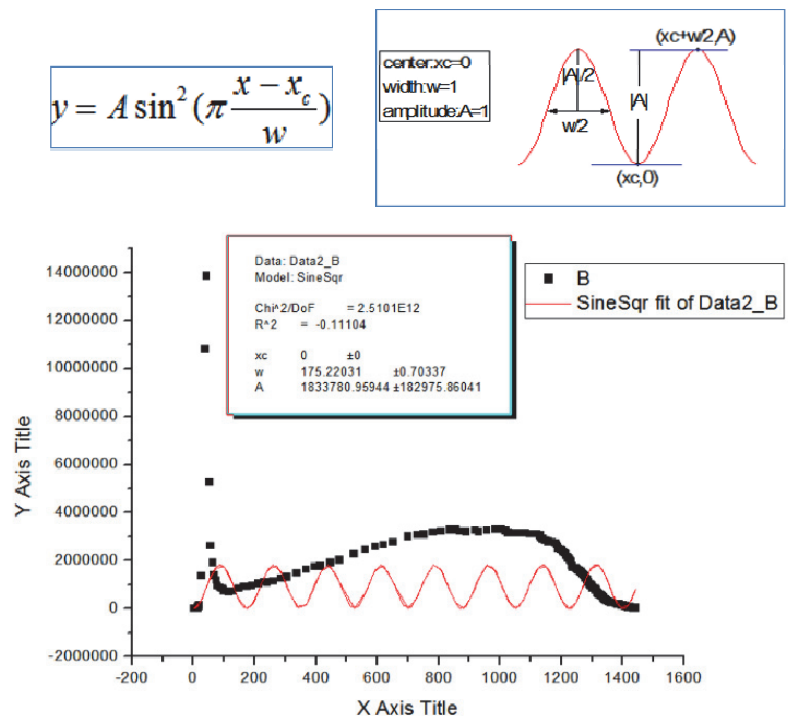

Yahoo. Thus, this helps decrease bias in the demographic composition of the web site's visitors. The sample consists of all 349 Korean films released during the period of 2008-2010. Specifically, the primary source of data for the volume of word-of-mouth (WOM) is the NAVER Movie site (http://movie.naver.com) (Yang, Kim, Amblee, \& Jeong, 2011). The negative expense and marketing expense data are both collected from articles, movie public relations (PR) information, and papers offered by the KOFIC. The data regarding the number of screens in theaters is collected from annual reports and official website of the KOFIC.

Before making a model we had to choose variables. So, we verified many variables which are distributor, producer, season, marketing cost, Genre, star power, WOM, Production Rate, rating whether what variables are effective to increase revenue. Among these variables we were finally able to choose critical variables in Table 2.

〈Table 2〉 Descriptive Statistics

\begin{tabular}{llll}
\hline Variable & Description of measure & Mean & Std. Dev. \\
\hline LNREV & Revenue & 13.058 & 3.012 \\
PR & Profit rate & 3.619 & 15.487 \\
LNNGT & Negative cost & 13.431 & 1.768 \\
LNWOM & Daily WOM volume & 6.252 & 2.117 \\
\hline
\end{tabular}




\subsection{Profit rate (PR)}

Profit rate is the return on investment measure, total revenues divided by the negative cost(Ravid, 1999). Revenue is a good indicator to assess economic performance since it contains not only box-office gross but also income through other distribution channels, so-called "window effect" (e.g. release in foreign market, DVD, pay television etc.) (Eliashberg, Elberse, \& Leenders, 2006). Thus, revenue has been used as a dependent variable in the earlier studies. However, the window effect in Korean film industry is insignificant. 88\% of revenue earned from box-office receipt in 2009, and the percentage of revenue from sales of theatre tickets has been increasing since the year 2000. In comparison with other countries, widely circu- $^{-}$ lated illegal download of movies and pirated copies impede the growth of home video market (VHS, DVD), remaining in $0.86 \%$ of total revenue in movie industry as of 2009. Also, exports to foreign markets tend to be increasing, but it reached about 4.12\% in 2009 (KOFIC, 2009). For this reason, revenue in this study is confined to the box office receipt, the total amount of money from the sale of tickets for movie. Here, negative cost is a production cost for final film, including actors' salaries, filming costs editing costs etc. Negative cost shows a highly positive correlation with star casting since negative cost includes star casting(Shugan, 2004).

\subsection{Production budget (LNNGT)}

Film production budgets also have received significant attention in the literature on motion picture economics. (Litman, 1983; Prag \& Casavant, 1994; Ravid, 1999) Big budgets translate into lavish sets and costumes, expensive digital manipulations, and special effects. Though big budgets are correlated with higher revenue, they are not correlated with returns. (S. Basuroy et al., 2003) Big budgets reflect higher quality and greater box office popularity. (S. Basuroy et al., 2003; Litman, 1983) Negative cost is the cost of producing the negative of the final film. This includes all aspects of the film's production: actors' salaries, editing, scenery, etc. Production cost is the indicator of a movie's quality(Prag \& Casavant, 1994) In general, though, big budgets are expected to show a noisy but positive correlation with film success. The same logic suggests that expenditures on advertising will be positively related to revenues. (Prag \& Casavant, 1994) There is a classification that a movie based on its box-office receipts in one of nine categories, ranging from 'flop' to 'blockbuster'. (Sharda \& Delen, 2006)

\section{Model}

To develop a new model, this research makes two assumptions. First, movie has the attrib- 
utes of a wave. To have the nature of a wave, a movie should have attributes such as interference and diffraction, as defined by natural science. According to previous studies, a movie may have the attribute of interference. When two movies are released together, we can find the effects of constructive interference and destructive interference. Thus, in order to reduce destructive interference among movies, distributors control their release dates. Second, the Schrödinger equation in quantum mechanics is applied to the movie industry. The Schrödinger equation explains how subatomic particles behave. Although the Schrödinger equation cannot be proved with classical mechanics, it is widely used because it accurately describes the wave function of a system, also called the quantum state. Likewise, because outliers in the movie industry cannot be explained with classical theory, the Schrödinger equation is applied.

Table 3 shows the conversion of the variables of the tunneling effect formula in physics into those in the movie industry. Although the overall format is similar, the detailed meanings of the variables differ. However, because movies have the attribute of a wave and we suggest valid evidences such as barrier of movie industry and importance of production cost and profit rate, and distribution of movies' revenue in advance, this study converted all variables of

$\langle$ Table 3〉 The relationship between physics and movies

\begin{tabular}{lll}
\hline Physics & Variable & Movie \\
\hline Particle Energy & E (Y axis) & Movie energy (Revenue) \\
\hline time & T (X axis) & Profit rate (Time dependent) \\
Mass & M & Production cost \\
Given Potential Energy & Barrier U & Length of highest revenue at three-sigma \\
Given Length & Barrier L & Length of standard deviation between \\
Planck Constant & $\hbar$ & one-sigma and three-sigma \\
Particle's tunneling probability & $\mathrm{T}$ & Cultural constant \\
\hline
\end{tabular}

〈Figure 10〉 Barrier and Length of Potential Energy

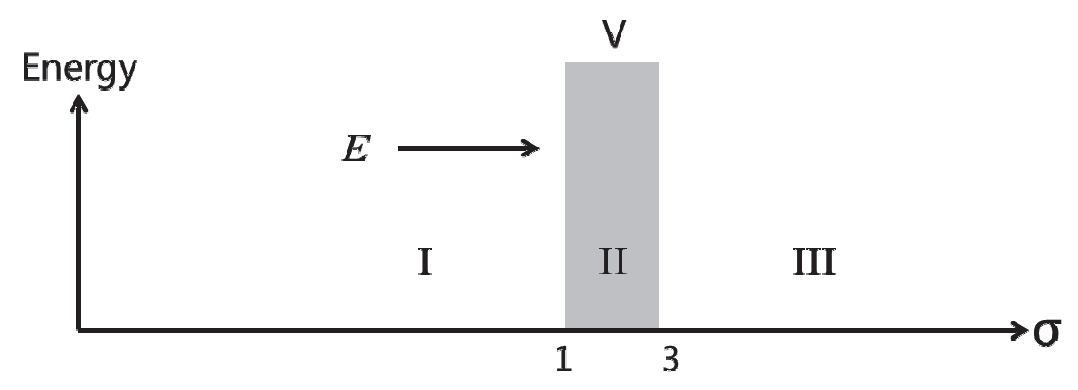


Schrödinger's equation into new variables for the movie industry. Thus, this paper should develop new meanings for these newly defined variables.

Figure 10 accounts for the defined variables in Table 3.

The form of this equation is from Schrödinger equation in quantum mechanics.

$$
\begin{aligned}
& \mathrm{T}=e^{\frac{-2 * l \sqrt{2 m(U-E)}}{C}} \\
& \mathrm{C}=\frac{-2 * L * \sqrt{2 m(U-E)}}{\ln T}
\end{aligned}
$$

From equations (1) and (2), we can forecast the range of the movie tunneling effect. Table 4 shows the change of the tunneling probability according to cases I, II and III.

\section{Result}

\subsection{Finding the Tunneling Effect in the Movie Industry}

We analyzed 349 movie distributions in terms of their production cost and profit rate. Only two movies which had recorded high profits were located in the outlier area, as shown in Figure 11.

The profit rate in the figure is revenue divided by product cost, which is return on investment (Ravid, 1999). The area of the $\mathrm{rec}^{-}$ tangle bounded by the $\mathrm{X}$ axis, the $\mathrm{Y}$ axis and two lines (one is a horizontal line from point $A$ to a point on the graph where $\mathrm{x}$ is zero; the other is a vertical line from point $A$ to a point on the graph where $\mathrm{y}$ is zero) represents the revenue of movie A. For example, the revenue of movie $\mathrm{C}$ in this figure is greater than that of movie $\mathrm{A}$, but the profit of movie $\mathrm{C}$ is lower than that of movie A.

Points A and B in Figure 11 are regarded as merely outliers and then discarded entirely when researchers have done their study and analysis concerning a performance of movie since the performance of these movies is far from 3-sigma range. Practically, for 3 years only 2 movies are included in the 3 sigma range. Then, how can we explain such exceptional cases? Should they be ignored as outliers according to other research? Outliers consist of observations that are numerically distant from the rest of the data. An outlier is one that appears to deviate

〈Table 4〉 Tunneling Probability Cases

\begin{tabular}{llll}
\hline Case & M & E & T \\
\hline I & Lower & Higher & $\uparrow$ \\
II & Lower & Lower & $\downarrow$ \\
III & Higher & Lower & $\downarrow$ \\
\hline
\end{tabular}


〈Figure 11〉 Relationship between Profit and the Negative Cost of Movies

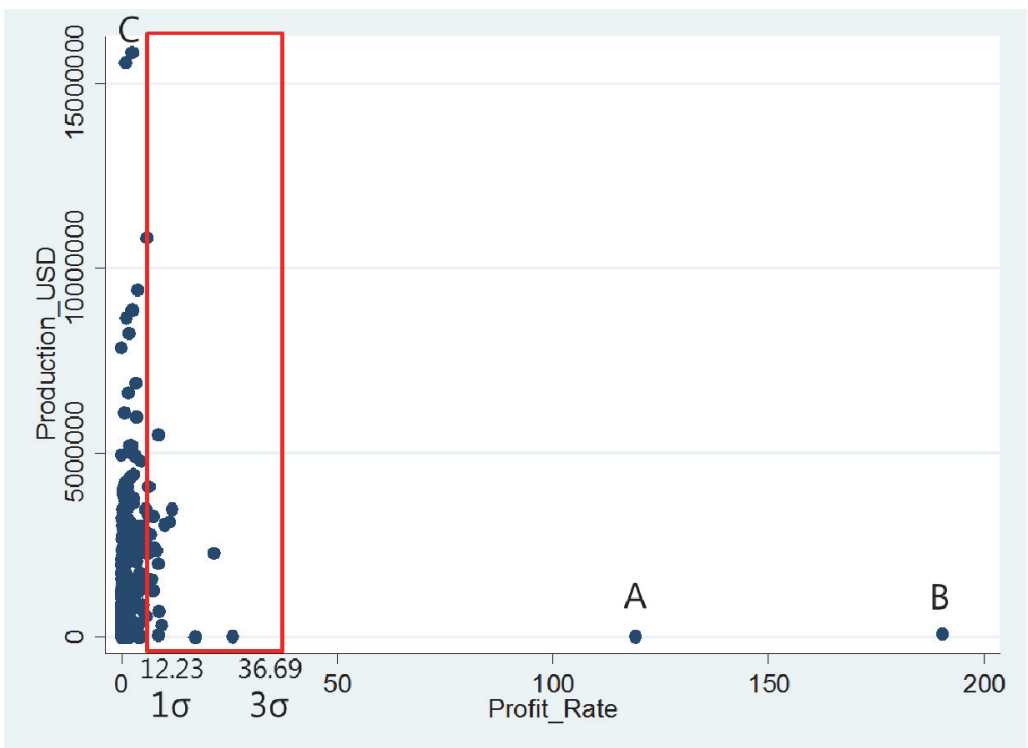

markedly from other members of the sample in which it occurs (Grubbs, 1969). In statistics, the 68-95-99.7 rule, or three-sigma rule, or empirical rule, states that for a normal distribution, nearly all values lie within 3 standard deviations of the mean. About $68.27 \%$ of the values lie within 1 standard deviation of the mean. Similarly, about $95.45 \%$ of the values lie within 2 standard deviations of the mean. Nearly all $(99.73 \%)$ of the values lie within 3 standard deviations of the mean.

From the given data, we can earn $\mathrm{T}=0.0057$, $\mathrm{L}=24.46, \mathrm{U}=581,189,596.1, \mathrm{E}=14,930,372, \mathrm{~m}=$ 78,381 according to Table 3 and then calculate the cultural constant h using equations (1) and (2). Therefore, the cultural constant is $\ln 24.287$ USD.Profit rate. Using cultural constant we are able to forecast the probability of finding outliers depended on given product cost before releasing movies. Thus, the investor can decide whether they put the money into the movie.

Figure 12 shows that a low-budget movie can tunnel through a given barrier standing in front of all movies and then move to an area of success, but at a very low probability. Points $A$ and $B$ can tunnel the barrier and then exist on the outlier area. That is, classical physics and social science cannot explain this experience without adopting tunneling effect theory of quantum mechanics.

\subsection{Why the Tunneling Effect Occurs in the Movie Industry}

Why does the tunneling effect appear in the movie industry? In order to determine why this 
〈Figure 12〉 Each Movie' Waves in Physics and the Barrier

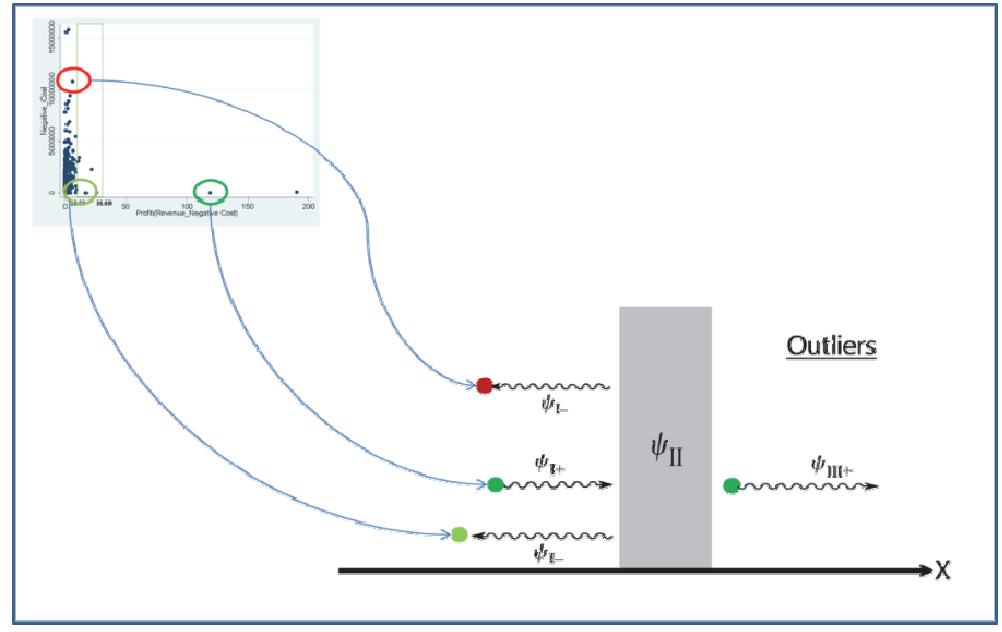

occurs, the daily revenue of each movie is traced in this study. A and B in Figure 13 represents the daily revenue trends for blockbuster films, $\mathrm{C}$ is that for mid-budget movies, and $\mathrm{D}$ is that for low-budget movies.

Figure 14 is a magnified image of Figure 11, showing the trend of the daily revenue of low- budget movie D. In general, low-budget films must expend much effort in their search for distributors, and they are released on a small number of screens. On the other hand, blockbusters take the majority of screens and handle publicity by spending their big budgets to produce grandiose marketing campaigns. Thus, low-

〈Figure 13〉 Several Movies' Daily Screen Fluctuation Patterns

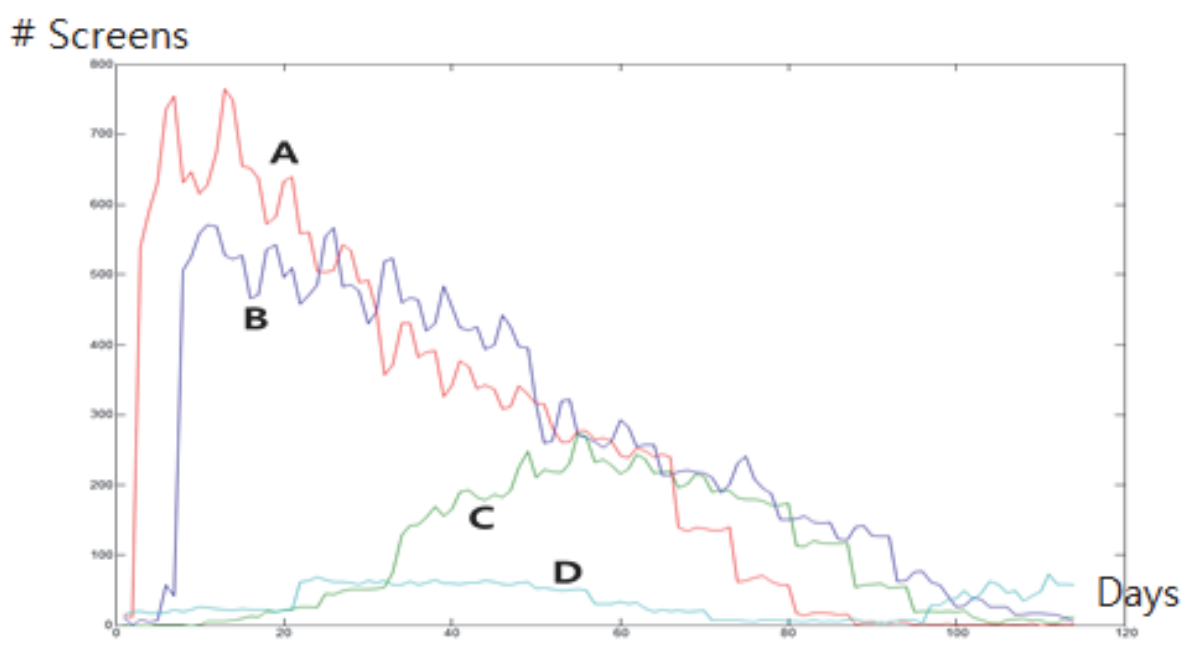

92 ASIA MARKETING JOURNAL Vol. 16 №. 03 October 2014 


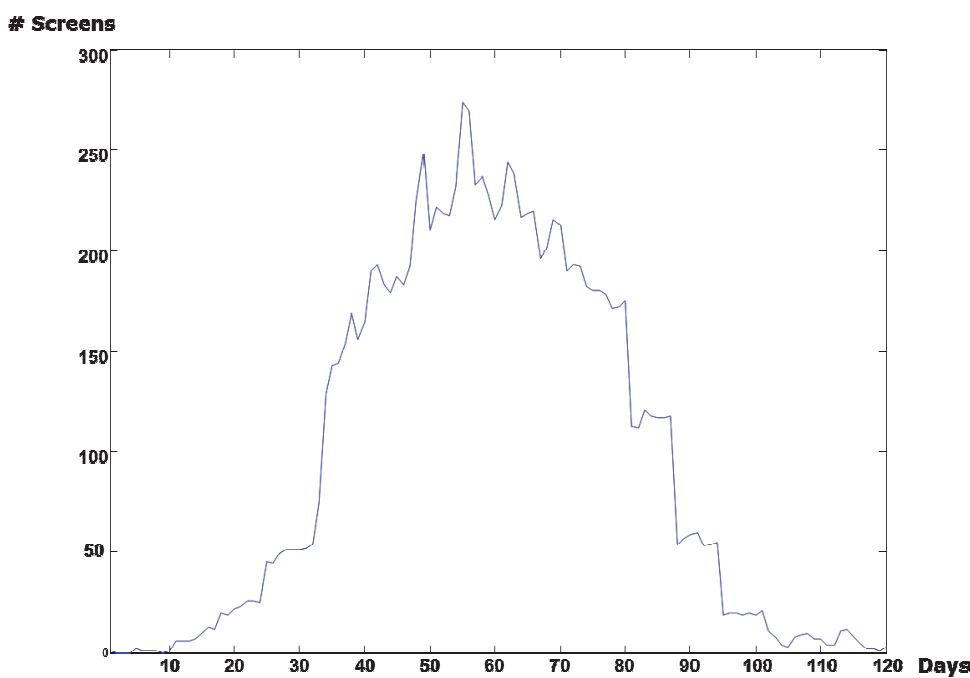

budget movies inherently lose opportunities to attract audiences. Also, in the standard drill, film distributors first release movies through movie theatres and stop distributing them at cinemas in approximately 16 weeks, as revenue, in general, is concentrated during the first two weeks after the release date. Figure 14 shows a trend by which the revenue of an outlier movie increases two weeks after its release, far from decreasing.

The unique pattern of outlier movies has to do with word-of-mouth (WOM). WOM in marketing has been defined as interpersonal communications between a non-commercial communicator and a receiver concerning a product or service' (Dichter, 1966). The elements of interpersonal communication differ from those of mass communication methods such as advertising. Marketing only influences the initial rollout of a film. After that, word-of-mouth plays a significant role. Viral marketing created by WOM is increasingly important in order to promote the sales of tickets. Figure 15 shows the trend of daily WOM with time. The blockbuster film A shows strong WOM for the first two weeks after its release, while the outlier film B's WOM slowly increases four weeks after its release.

The trend of daily revenue and the trend of word-of-mouth show similar patterns, as shown in Figure 13 and Figure 15. This finding suggests that in general there is a strong relationship between revenue and word-of-mouth. This finding is consistent with previous studies showing that WOM strongly influences people's movie selections (Bayus, 1985; Neelamegham \& Chintagunta, 1999). 
〈Figure 15〉 Blockbuster and Outliers' Daily Word-of-mouth Fluctuation Patterns

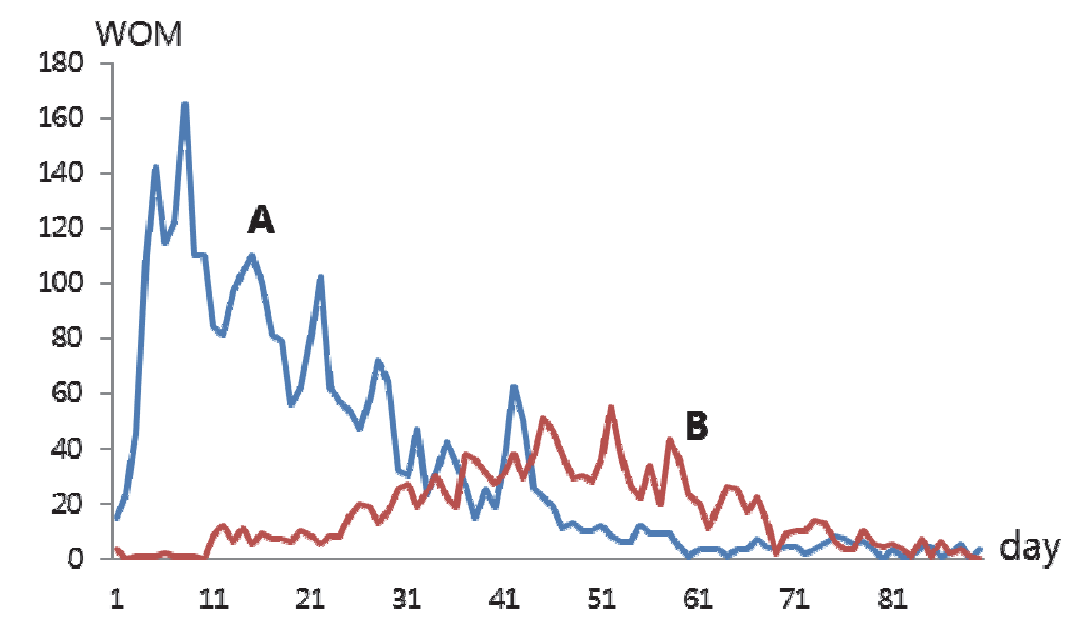

\section{Conclusion}

This study developed a methodology for analysing cases of low-budget movies that broke conventions to garner a growing audience over time despite the reality of today's movie market dominated by blockbusters. Since these cases are rare in the movie market, the shortage in samples meant that there were limitations to applying existing quantitative analysis methods to analyse this small number of cases. That is why only qualitative analysis methods had been used in former analyses. This research, however, makes use of the concept of tunnelling effect model in quantum mechanics and the Schrödinger equation in analysing movie variables and data. Thus, this study is differentiated from previous studies in that it attempted to explain the success of outliers in the movie in- dustry by applying the tunnel effect. Through this process, a tunnelling effect model for the movie market was developed and a movie constant was deducted. This model and movie constant can be applied to calculate the probability being included in the outlier level according to the level of movie production costs. This study may be the first attempt to find the critical factors that influence the box-office success of low-budget movies using mathematical methods commonly used in quantum mechanics. The important findings in this study are discussed below.

First, we were able to predict (1) the probability of success in recording an extraordinarily high profit rate beyond three-sigma prior to production, (2) the production cost given the profit rate, and (3) the probability of achieving a high profit margin in other cultural products such as musical plays and music.

Second, it is very difficult to enter the three- 
sigma outlier area for blockbuster movies which spend an enormous amount of money on production because the size of the movie market is limited. Considering the limited size of the movie industry, the tunneling effect is more likely to be observed in relation to low-budget movies. Horror movies have traditionally been a favorite with audiences and low-budget filmmakers, as we have seen with 'Paranormal Activity.' Comedies and documentary films are also viable, providing a large payoff. In addition, the analysis showed that the reason such a tunneling effect could take place was the influence that word-of-mouth promotion yields. As such, it presents word-of-mouth promotion as an effective strategy in boosting profit in the movie market.

Finally, the empirical findings in this paper can help researchers gain a trusty result through quantitative analysis and scientific access unlike if the findings were determined using only a qualitative analysis. In addition, this study supports marketing researchers in their efforts to explain tipping point phenomena and chasm theory quantitatively.

〈Received February 10. 2014〉

〈Revised August 26. 2014〉

〈Accepted October 28. 2014〉

\section{References}

Ainslie, A., Drèze, X., \& Zufryden, F. (2005). Modeling movie life cycles and market share. Marketing Science, 508-517.

Bagella, M., \& Becchetti, L. (1999). The determinants of motion picture box office performance: Evidence from movies produced in Italy. Journal of Cultural Economics, 23 (4), 237-256.

Baggett, P. (1979). Structurally equivalent stories in movie and text and the effect of the medium on recall. Journal of Verbal Learning and Verbal Behavior, 18(3), 333356.

Basuroy, S., Chatterjee, S., \& Ravid, S. A. (2003). How critical are critical reviews? The box office effects of film critics, star power, and budgets. Journal of Marketing, 103-117.

Basuroy, S., Chatterjee, S., \& Ravid, S. A. (2003). How critical are critical reviews? The box office effects of film critics, star power, and budgets. Journal of Marketing, 67(4), 103-117.

Bayus, B. L. (1985). Word of Mouth-the In0 direct Effects of Marketing Efforts. Journal of advertising research, 25(3), 31-39.

Bergstrand, J. H. (1985). The gravity equation in international trade: some microeconomic foundations and empirical evidence. The review of economics and statistics, 474-481. 
Chakravarty, A., Liu, Y., \& Mazumdar, T. (2010). The Differential Effects of Online Word-of-Mouth and Critics' Reviews on Pre-release Movie Evaluation. Journal of Interactive Marketing, 24(3), 185-197. doi: DOI 10.1016/j.intmar.2010.04.001

Chowdhury, D., Santen, L., \& Schadschneider, A. (2000). Statistical physics of vehicular traffic and some related systems. Physics Reports, 329(4), 199-329.

Dalton, M. A., Sargent, J. D., Beach, M. L., Titus-Ernstoff, L., Gibson, J. J., Ahrens, M. B., . . Heatherton, T. F. (2003). Effect of viewing smoking in movies on adolescent smoking initiation: a cohort study. The Lancet, 362(9380), 281-285.

De Palma, A., Ben-Akiva, M., Lefevre, C., \& Litinas, N. (1983). Stochastic equilibrium model of peak period traffic congestion. Transportation Science, 17(4), 430-453.

De Vany, A., \& Walls, W. (2004). Big budgets, big openings and legs: Analysis of the blockbuster strategy. Asian Economic Review, 47(2), 308-328.

De Vany, A., \& Walls, W. D. (1999). Uncertainty in the movie industry: Does star power reduce the terror of the box office? Journal of Cultural Economics, 23(4), 285318.

De Vany, A., \& Walls, W. D. (2002). Does Hollywood Make Too Many R Rated Movies? Risk, Stochastic Dominance, and the Illusion of Expectation*. The Journal of Business, 75(3), 425-451.

Dichter, E. (1966). \{How word-of-mouth advertising works\}. Harvard business review, 44(6), 147-160.

Eliashberg, J., Elberse, A., \& Leenders, M. A. A. M. (2006). The motion picture industry: Critical issues in practice, current research, and new research directions. Marketing Science, 638-661.

Fratianni, M., \& Kang, H. (2006). Heterogeneous distance - elasticities in trade gravity models. Economics Letters, 90(1), 68-71.

Gazley, A., Clark, G., \& Sinha, A. (2011). Understanding preferences for motion pictures. Journal of Business Research, 64(8), 854861. doi: 10.1016/j.jbusres.2010.09.012

Grubbs, F. E. (1969). Procedures for Detecting Outlying Observations in Samples. Technometrics, 11(1), 1-21. doi: 10.1080/00401706. 1969.10490657

Holbrook, M. B. (1999). Consumer value: a framework for analysis and research: Psychology Press.

Litman, B. R. (1983). Predicting success of theatrical movies: An empirical study. The Journal of Popular Culture, 16(4), 159-175.

Neelamegham, R., \& Chintagunta, P. (1999). A Bayesian model to forecast new product performance in domestic and international markets. Marketing Science, 115-136.

Piperakis, A. S., Milner, C., \& Wright, P. W. (2003). Immigration, trade costs and trade: gravity evidence for Greece. Journal of 
Economic Integration, 18(4), 1-13.

Prag, J., \& Casavant, J. (1994). An empirical study of the determinants of revenues and marketing expenditures in the motion picture industry. Journal of Cultural Economics, 18(3), 217-235.

Ravid, S. A. (1999). Information, Blockbusters, and Stars: A Study of the Film Industry*. The Journal of Business, 72(4), 463-492.

Ravid, S. A. (2004). Are they all crazy or just risk averse? Some movie puzzles and possible solutions. Contributions to economic analysis, 260, 33-48.

Sargent, J. D., Beach, M. L., Dalton, M. A., Ernstoff, L. T., Gibson, J. J., Tickle, J. J., \& Heatherton, T. F. (2004). Effect of parental R-rated movie restriction on adolescent smoking initiation a prospective study. Pediatrics, 114(1), 149-156.
Sharda, R., \& Delen, D. (2006). Predicting box-office success of motion pictures with neural networks. Expert Systems with Applications, 30(2), 243-254.

Shugan, S. M. (2004). Editorial: Endogeneity in marketing decision models. Marketing Science, 1-3.

Smith, S. P., \& Smith, V. K. (1986). Successful movies: A preliminary empirical analysis. Applied Economics, 18(5), 501-507.

Sochay, S. (1994). Predicting the performance of motion pictures. Journal of Media Economics, 7(4), 1-20.

Yang, J., Kim, W., Amblee, N., \& Jeong, J. (2011). The Heterogeneous Effect of WOM on Product Sales: Why the Effect of WOM Valence is Mixed?

Wikipedia.com 


\section{$\langle$ Appendix〉}

Tunneling effect Schrödinger Equation

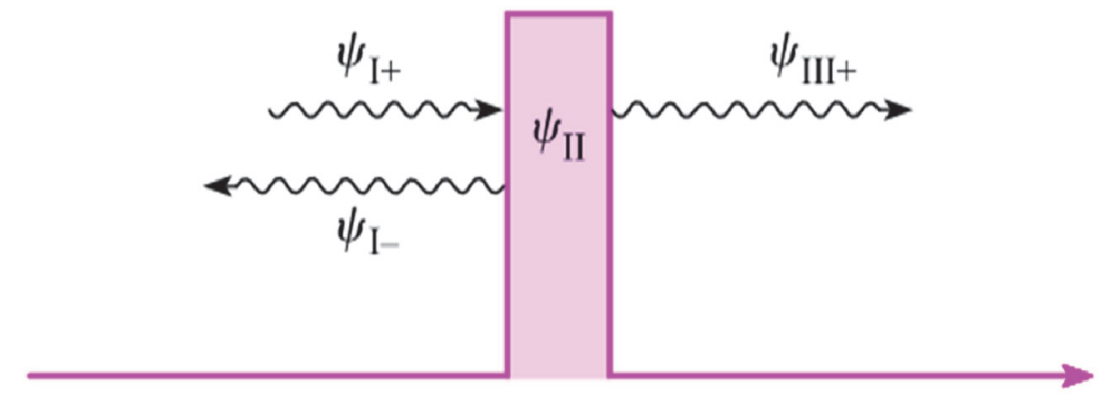

1. Schrödinger Equation of I and III area at $U=0$

$$
\begin{aligned}
& \frac{d^{2} \psi_{\mathrm{I}}}{d x_{2}}+\frac{2 m}{\hbar^{2}} E \psi_{\mathrm{I}}=0 \\
& \frac{d^{2} \psi_{\mathrm{III}}}{d x^{2}}+\frac{2 m}{\hbar^{2}} E \psi_{\mathrm{III}}=0
\end{aligned}
$$

The value of the equation is

$$
\begin{aligned}
& \psi_{\mathrm{I}}=A e^{i k_{\mathrm{I}} x}+B e^{-i k_{1} x} \\
& \psi_{\mathrm{III}}=F e^{i k_{1} x}+G e^{-i k_{1} x} \\
& \psi_{\mathrm{I}+}=A e^{i k_{1} x}
\end{aligned}
$$

(A: amplitude)

Wave number is

$$
\begin{aligned}
& k_{1}=\frac{\sqrt{2 m E}}{\hbar}=\frac{p}{\hbar}=\frac{2 \pi}{\lambda} \\
& e^{i \theta}=\cos \theta+i \sin \theta \\
& e^{-i \theta}=\cos \theta-i \sin \theta \\
& S=\left|\psi_{\mathrm{I}+}\right|^{2} v_{I+}
\end{aligned}
$$

$\mathrm{S}$ : \# of particles per square meter per second Reflected wave; $\psi_{\mathrm{I}-}=B e^{-i k_{1} x}$ 
$\therefore$ Wave function at area I

$$
\psi_{\mathrm{I}}=\psi_{\mathrm{I}+}+\psi_{\mathrm{I}-}
$$

Where, $x>L$

Penetrated wave; $\psi_{\mathrm{III}+}=F e^{i k_{1} x}$

2. Tunneling probability is the rate between fluxes of in and out.

$$
T=\frac{\left|\psi_{I I I+}\right|^{2} v_{I I I+}}{\left|\psi_{I+}\right|^{2} v_{I+}}=\frac{F F^{*} v_{I I I+}}{A A^{*} v_{I+}}
$$

Schrödinger Equation for the particle in Region II is

$$
\frac{d^{2} \psi_{I I}}{d x^{2}}+\frac{2 m}{\hbar^{2}}(E-U) \psi_{I I}=\frac{d^{2} \psi_{I I}}{d x^{2}}-\frac{2 m}{\hbar^{2}}(U-E) \psi_{I I}=0
$$

Where, $\mathrm{U}>\mathrm{E}$

Wave function inside barrier

$$
\psi_{I I}=C e^{-k_{2} x}+D e^{+k_{2} x}
$$

Wave number inside barrier

$$
k_{2}=\frac{\sqrt{2 m(U-E)}}{\hbar}
$$

Assumption; where, $\mathrm{x}=0$

$$
\begin{aligned}
& \psi_{I}=\psi_{I I} \\
& \frac{d \psi_{I}}{d x}=\frac{d \psi_{I I}}{d x}
\end{aligned}>\quad x=0
$$

Assumption; where, $\mathrm{x}=\mathrm{L}$

$$
\left.\begin{array}{l}
\psi_{I I}=\psi_{I I I} \\
\frac{d \psi_{I I}}{d x}=\frac{d \psi_{I I I}}{d x}
\end{array}\right\} \quad x=\mathrm{L}
$$


From $\Psi_{\mathrm{I}}, \Psi_{\mathrm{II}}, \Psi_{\mathrm{III}}$

$$
\begin{aligned}
& A+B=C+D \\
& i k_{1} A-i k_{1} B=-k_{2} C+k_{2} D \\
& C e^{-k_{2} L}+D e^{k_{2} L}=F e^{i k_{1} L} \\
& -k_{2} C e^{-k_{2} L}+k_{2} D e^{k_{2} L}=i k_{1} F e^{i k_{1} L}
\end{aligned}
$$

Let's solve $(\mathrm{A} / \mathrm{F})$

$$
\begin{aligned}
& \left(\frac{A}{F}\right)=\left[\frac{1}{2}+\frac{i}{4}\left(\frac{k_{2}}{k_{1}}-\frac{k_{1}}{k_{2}}\right)\right] e^{\left(i k_{1}+k_{2}\right) L}+\left[\frac{1}{2}-\frac{i}{4}\left(\frac{k_{2}}{k_{1}}-\frac{k_{1}}{k_{2}}\right)\right] e^{\left(i k_{1}-k_{2}\right) L} \\
& \left(\frac{A}{F}\right)=\left(\frac{1}{2}+\frac{i k_{2}}{4 k_{1}}\right) e^{\left(i k_{1}+k_{2}\right) L}
\end{aligned}
$$

If barrier's potential is bigger than $\mathrm{E}(\mathrm{U}>\mathrm{E}), \mathrm{k}_{2} / \mathrm{k}_{1}>\mathrm{k}_{1} / \mathrm{k}_{2}$.

$$
\frac{k_{2}}{k_{1}}-\frac{k_{1}}{k_{2}} \approx \frac{k_{2}}{k_{1}}
$$

From $\mathrm{V}_{\mathrm{III}+}=\mathrm{V}_{\mathrm{I}+}$

Tunneling Probability

$$
\begin{aligned}
& T=\frac{F F^{*} v_{I I++}}{A A^{*} v_{I+}}=\left(\frac{A A^{*}}{F F^{*}}\right)^{-1}=\left[\frac{16}{4+\left(k_{2} / k_{1}\right)^{2}}\right] e^{-2 k_{2} L} \\
& k_{1}=\frac{\sqrt{2 m E}}{\hbar}=\frac{p}{\hbar}=\frac{2 \pi}{\lambda}, k_{2}=\frac{\sqrt{2 m(U-E)}}{\hbar}
\end{aligned}
$$

That is,

$$
\left(\frac{k_{2}}{k_{1}}\right)^{2}=\frac{2 m(U-E) / \hbar^{2}}{2 m E / \hbar^{2}}=\frac{U}{E}-1
$$

Therefore, approximate tunneling probability is calculated as

$$
T=e^{-2 k_{2} L}
$$

$\rightarrow$ Particle's energy and length of barrier of potential determines the tunneling probability. 